\title{
Sustainable development: understanding the concept and practical challenge
}

\section{S. Parkin, F. Sommer and S. Uren}

\section{T. G. Carpenter}

The authors have reiterated the UK Government's 1999 objectives for sustainable development and have updated their explanation of concepts such as the five capitals framework. They have discussed comprehensively the 'contexts and drivers' for sustainable development in Britain but recognise that change is 'taking place more slowly than either the state of the environment or the global market opportunities would seem to dictate.' To speed up the change I contend that governments should revise their priorities and intervene more strongly; and I wonder whether 'business and the engineering profession' are ready for all the opportunities that could then result.

Of the UK Government's four objectives, prudent use of natural resources is surely the most important; and it is one civil engineers can significantly influence. Any protection of the environment that is not conserving natural resources or the climate is likely to be a social issue. Social progress itself is related to construction, for example in public health engineering, but relevant to sustainable development more as a reminder that the benefits of resource use should be shared fairly. But the fourth Government objective, concerning economic growth, seems in 2003 to be both optimistic and inappropriate as an element of sustainable development-at best a red herring, at worst an excuse for short-term expedience. 'Employment levels' are an important aspect of social progress but 'high and stable levels of economic growth' seem increasingly incompatible with the prudent use of natural resources, particularly as all the objectives apply 'in the UK and the world as a whole'. Indeed high or even any positive economic growth in an already rich country may constitute a direct obstacle to global resource conservation.

Forum of the Future's five capitals framework (their headings (listed in italicised text), my comments (shown in normal text)) comprises the following.

(a) Natural capital-land, water, biotic life, minerals, fossil fuels - with which civil engineers 'direct the great sources of power in Nature for the use and convenience of man' (ICE Constitution ${ }^{34}$ ) while 'improving and maintaining the built and natural environments' (ICE Members' Guide ${ }^{35}$ ).

(b) Human capital which is ingenuity and effort-with severe limitations where there are too many people for the available resources. (c) Social capital which relates to civilised humanity and its organisations for collaboration, from families up to governments.

(d) Manufactured capital where, for example in some robust structures, we have a useful heritage that should be sacrificed only with caution.

(e) Financial capital - money — which the authors' Fig. 3 describes as a means of valuing, owning and exchanging the other four capitals.

That definition of financial capital conjures up markets. One current philosophy is that markets should be 'free'. However, unconstrained market forces accelerate unsustainable and inequitable natural resource depletion. The need for stronger government intervention is therefore urgent. The most effective instruments for intervention are fiscal; and, in long-term demand management, taxation is usually more effective than subsidy.

If developers are to be restrained from building on greenfield sites they could be discouraged by taxes on rural land development but encouraged by land-value taxation to redevelop disused city land. Location of houses and workplaces in the countryside would also be less attractive if there were much higher taxes on fuel for the road transport on which they utterly depend. By the same token, people would not have moved in such numbers to Florida or Phoenix, Arizona, if electricity for air-conditioning had not been so cheap. Governments have somehow to persuade voters of the necessity for certain methods of taxation and indeed certain types of constructed facility. Government action leading to new economic values should eventually result in more sustainable lifestyles. Higher taxes to prevent resource depletion may be balanced by reduction in more arbitrary taxes or greater public investment in social progress or environmental protection.

The practical challenge is evidently aimed at people who

(a) work for the construction industry, using energy, quarried or recycled materials and creating waste while also striving to establish a green and ethical corporate reputation

(b) work for client organisations (such as BAA or some government departments) who operate commercially or within budgets but also report on their sustainability 
indicators and triple-bottom-line (environmental/economic/social) performance

(c) are in-house engineers or consultant firms helping the other two categories to plan and design their construction projects while introducing intelligent materials and clean technology and incorporating life-cycle and risk assessment.

These people's activity covers a great deal of important construction-from flood alleviation works in Britain to water engineering schemes in drier countries. Then there are roads, airports and power plants, also planned on environmental principles but sometimes contentious as to whether or not they are part of long-term sustainable strategies, for example for transport or energy. Meanwhile the onus on engineers is to do what they can to

(a) be ready for new challenges when political constraints are released, for example by planning how to construct new nuclear power stations on the same sites as partly decommissioned ones

(b) prove that, in the same example, nuclear waste can be stored and monitored safely and indefinitely underground.

Similar challenges will have to be met to solve technical and constructional problems in extending wind electricity generation and other less proven renewable energy sources to anything like the scale envisaged by government; and new approaches will be needed to adapt infrastructure to reduced energy consumption. In hot or arid countries there are pressing problems in providing water for still growing populations. The authors mention big dams in India and Turkey. The need to store water for the economic survival of increasing populations demands reservoirs. Dam project costs must include full social compensation; but resettlement of displaced communities is only one element of the greater regional problem of accommodating ever more people sustainably. Meanwhile conserving the capacity of reservoirs subject to sedimentation is a practical problem still requiring huge ingenuity and investment.

\section{Authors' reply}

This commentator rightly notes the different elements of sustainable development but we would underline that sustainable development means progressing them all, at the same time. It has been the past practice of progressing one at the expense of another that has led to unsustainable development.

The first step to doing this of course is to think of all elements together. Not easy when they are usually dealt with in separate government departments, taught in different faculties at universities and schools, and even discussed on separate pages in the newspaper and journals. But not impossible. Engineers have the opportunity to give a lead as they are trained to think of the multiple aspects of any problem, and to finding solutions to individual problems through thinking or rethinking the whole project. All aspects of sustainability-environmental, human, social, manufactured and financial capital enhancement - are therefore the business of all engineers.

Getting the price right in the marketplace is, of course, a vital component of moving towards a sustainable way of doing things. At the moment, profligacy with resources (and therefore generation of waste and pollution) is rewarded by the way the national accounts are done. So shifting incentives to reward resource 'productivity', and recognising the value to human and social capital in the national accounts is important.

We would also argue that appropriate policy interventions by governments can also be a vital component towards more sustainable development. Businesses alone can not respond to the challenges presented by the need for more sustainable construction.

\section{J. Benjafield}

With regard to their paper on sustainable development, I would like to offer some comments for the authors' response.

(a) I believe that the majority of professional engineers have understood the concept of sustainable development for a very long time: the real problem has been one of convincing clients, governments and the general public of the concept because of the extra costs often associated with the better thought-out projects.

(b) The authors identify five 'capitals'. I suggest that a sixth should be added; namely that of time which is finite for all of us and expresses the limited window of opportunity which arguably (but not conclusively) exists for the realignment of development goals and policies.

(c) Para. 2.1, item (d) of the paper states that the UK construction industry throws away unused 13 million tonnes of material delivered to sites per annum. This seems an incredible amount given that, for example, some builders now expect their sites to account in detail for all materials used. Regrettably, theft is the more likely cause for such wastage.

(d) I feel the examples given (backing horses and Who Wants to be a Millionaire?) to indicate the capacity of ordinary people to conduct speedy and sophisticated calculations are misleading: the vast majority get it wrong and don't win anything. In fact a 'sustainability analysis' would surely conclude that their effort and resources were arguably misplaced although doubtless pleasurable. I would agree that ordinary people are quite capable of coming to a rational conclusion if given all the facts and if allowed to interact with the engineers and other professionals involved in proposed developments. However, there are several major difficulties which mitigate against this ideal state of affairs.

(i) The tendency for government in all forms to avoid full disclosure for political reasons and sometimes security reasons.

(ii) Commercial practices and pressures prevent companies from disclosing future plans and developments to shopfloor workers, shareholders and the public alike. Such plans and developments may depend in some cases on secret negotiations with government. The final decision on what and where to manufacture often rests solely with a board of directors which in effect is responsible to no one except itself providing the outcome is successful commercially.

(iii) The understandable unwillingness of ordinary people to continuously invest the time necessary for a full understanding of all the issues at stake in major new developments and to communicate their considered 
opinion to elected representatives and others, particularly when they have good reason to believe that their views will be ignored (the paper refers to "public scepticism').

(e) The paper refers to the need for evaluation transparency and essential scientific rigour in view of the difficulties of decision making in the context of sustainable development and increasing technological sophistication because of the increasing 'price of getting it wrong'. It then goes on to refer to the 'it' criteria. By way of clarification, could the authors give some specific examples to illustrate that these prices are really increasing and where we have 'got it wrong' in the past? (I could provide many myself but I am interested in the authors' views.)

$(f)$ Are we reaching a stage where lifetime per capita energy consumption will have to be rationed so that in aggregate it does not exceed worldwide sustainability? Such a concept implies imposing limits to population growth as well as limits to per capita energy consumption.

(g) Increasing bureaucracy in the developed world is one of the biggest wastes of scarce resources. There are millions of highly trained people engaged in administrative work, which is neither directly productive nor significantly evaluative or supportive, who command good salaries and consume the product of a numerically declining workforce. Efforts directed towards sustainable development are likely to increase this bureaucracy, as more demands are made for evaluation and debate before implementation, and lead to procrastination rather than decision making.

\section{Authors' reply}

We would agree wholeheartedly with the commentator's opening remarks highlighting that while engineers have understood the concept of sustainable development for quite some time, problems associated with delivery of the concept have been associated with failure to convince clients, etc., partly due to the extra costs involved. This highlights a real need to express financial costs within longer-term frameworks and, critically, to begin to place a financial value on the environmental and social benefits associated with more sustainable construction. We would therefore strongly advocate the adoption of sustainabillity accounting techniques within the wider industry.

The commentator rightly notes the criticality of time as a factor in the delivery of more sustainble development; in other words there is a finite period available for the 'realignment of development goals and policies'. Time, however, is not a capital in the same way as environmental or human resource; time is both a driver for sustainable development and a way of measuring progress.

The commentator moves on to an analysis of factors which could mitigate against the ability of the general public to reach technically and socially complex decisions (and in so doing, promote more sustainable development). We would argue that the description of commercial practices is unecessarily bleak, as there have been significant moves by many large organisations to deliver greater transparency in their dialogue processestangible stakeholder pressure is resulting in much greater levels of disclosure than seen previously. Similarly, changes in corporate governance structures are increasing the accountability of boards of directors, such that increasing numbers of investors within the City now want to know about environmental and social risks, as well as predicted financial out-turn.

\section{REFERENCES}

34. Institution of Civil Engineers. ICE Constitution. ICE, London.

35. Institution of Civil Engineers. Members' Guide. See http:// www.ice.org.uk for more details. 